\title{
AVALIAÇÃO DO TRABALHO DOS FUNCIONÁRIOS EM RESTAURANTE SOB O VIÉS DA PSICOLOGIA AMBIENTAL E DA ERGONOMIA
}

\author{
SOUZA, Rodrigo Vargas (1); \\ SNOWARESKI, Heloísa Honorato (2); \\ CARDOSO, Luciana Silveira (3); \\ BINS ELY, Vera Helena Moro (4) \\ (1) Universidade Federal de Santa Catarina, Doutorando em Arquitetura e Urbanismo \\ e-mail: arquitetura.rodrigo@hotmail.com \\ (2) Universidade Federal de Santa Catarina, Mestranda em Arquitetura e Urbanismo \\ e-mail: heloisa honorato@hotmail.com \\ (3) Universidade Federal de Santa Catarina, Doutoranda em Arquitetura e Urbanismo \\ e-mail: lucianascmuseu@gmail.com \\ (4) Universidade Federal de Santa Catarina, Doutora em Engenharia de Produção \\ e-mail: vera.binsely@gmail.com
}

\begin{abstract}
RESUMO
Diante da necessidade de adequação do ambiente construído aos usuários e às atividades desenvolvidas, este artigo apresenta um estudo de caráter investigativo e qualitativo em um restaurante localizado na cidade de Florianópolis, SC. Para isto foram utilizados os seguintes métodos: pesquisa bibliográfica, visita exploratória, entrevista semiestruturada com funcionários e proprietários, observação do ambiente, análise antropométrica, questionário nórdico, poema dos desejos e medição do conforto ambiental (temperatura e umidade, ruído e iluminação). Os resultados permitiram identificar os principais problemas e desenvolver recomendações de correções e melhorias na edificação estudada.
\end{abstract}

Palavras chave: Arquitetura Comercial, Psicologia Ambiental, Avaliação Pós-Ocupação (APO), ergonomia.

\begin{abstract}
According to the need to adapt the built environment to users and the activities developed, this article presents a research and qualitative study in a restaurant located in the city of Florianópolis, SC. What are the methods: literature review, exploratory research, semi-structured interview with employees and owners, environmental observation, anthropometric analysis, Nordic questionnaire, poem of wishes and measurement of environmental comfort. The results allowed to identify the main problems and to develop recommendations of corrections and improvements of the studied building.
\end{abstract}

Keywords: Commercial Architecture, Environmental Psychology, Post-Occupancy Evaluation (POE), ergonomics. 


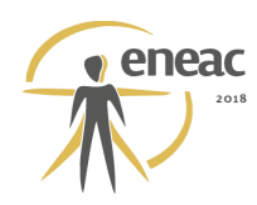

\section{INTRODUÇÃO}

A arquitetura sempre teve como primeiro objetivo 0 atendimento às expectativas dos usuários, desde os aspectos básicos de habitabilidade até a fruição estética que a edificação pode proporcionar ao ser humano (VOORDT; WEGEN, 2013).

Os ambientes comerciais, sobretudo os de alimentação, são umas das principais áreas de atuação de projetistas, arquitetos e designs de interiores, nos dias de hoje, devido a crescente demanda do setor. No atual contexto, o predomínio dos investimentos do setor comercial, bem como dos estudos da área diz respeito aos aspectos direcionados diretamente ao cliente e seu potencial de consumo. Porém ainda há uma lacuna sobre as necessidades e satisfação de seus trabalhadores. Kopec (2010) afirma que para ser bem sucedido, um estabelecimento comercial deve garantir tanto a satisfação de seus clientes como de seus funcionários.

Muitos fatores contribuem para o sucesso de um ambiente de varejo. Embora alguns aspectos de um ambiente agradável possam passar despercebidos aos seus usuários, um ambiente problemático ou com limitações espaciais pode facilmente criar uma impressão negativa (KOPEC, 2010). A carência de trabalhos científicos nesta área, que contempla os campos da arquitetura, ergonomia e psicologia ambiental, aponta para a necessidade de estudos interdisciplinares de forma a compreender as necessidades dos indivíduos, buscando melhorar a qualidade de vida nos ambientes comerciais, sendo bom, para os usuários e para os negócios.

Segundo Ornstein (2005) a interdisciplinaridade se justifica, na medida em que outras ciências, além das relacionadas à arquitetura - tais como ergonomia e psicologia ambiental

- são relevantes para uma maior fundamentação das ações planejadas na avalição pósocupação (APO).

É importante entender as necessidades do usuário na realização de determinada tarefa para identificar quais os fatores que concorrem para a qualidade ambiental. Assim torna-se imprescindível a aplicação de métodos de avaliação pós-ocupação que busquem a descrição desses fatores, a partir da observação do comportamento dos usuários e da declaração ou revelação de suas preferências.

\section{OBJETIVO}

O objetivo deste trabalho é avaliar aspectos relacionados à qualidade ambiental de um restaurante, a fim de produzir recomendações que contribuam para o bem-estar de seus usuários e para a qualidade espacial do estabelecimento estudado.

\section{METODOLOGIA}

Neste artigo foram utilizados diferentes métodos, provenientes de diferentes disciplinas, descritos a seguir.

A pesquisa bibliográfica foi realizada para obter informações sobre a classificação da profissão e normas regulamentadoras dos funcionários atendentes.

Buscou-se inicialmente conhecer o ambiente e os estímulos do meio a partir de visitas exploratórias, nas quais foram realizados registros fotográficos, levantamento dimensional do espaço físico e mobiliário e medição do conforto ambiental (temperatura e umidade, ruído e iluminação) em diferentes pontos, tanto no ambiente interno como externo com o sensor MC 350. Contou-se, ainda, com uma entrevista semiestruturada com o proprietário e com os 


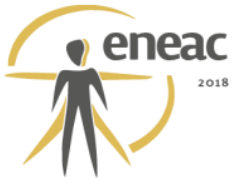

funcionários para entender a história do estabelecimento e a composição de seu corpo laboral e rotinas.

Em uma segunda etapa, deu-se início à fase de levantamento de dados, em que se buscou o projeto arquitetônico do estabelecimento, seguido por observações dos traços físicos que, segundo Zeisel (2006), servem para identificar como os usuários se comportam no ambiente a partir de vestígios deixados pelas atividades realizadas. Também foi feito o mapeamento comportamental que possibilitou identificar os comportamentos e contatos sociais, bem como entender o perfil dos usuários, suas rotinas de atividades e possíveis zonas de ocupação, e seus principais fluxos (RHEINGANTZ, 2009).

Para avaliar a percepção dos funcionários em relação ao ambiente e obter dados sobre as atividades que cada um realiza, foram utilizadas entrevistas semiestruturadas com apoio de três questionários. O primeiro buscou identificar quais as principais atividades que os funcionários realizam. O segundo questionário focou nos atributos físicos-espaciais e, o terceiro - o questionário nórdico (Kuorinka et al., 1987) - investigou os distúrbios osteomusculares. Também foi aplicado o poema dos desejos criado por Henry Sanoff (SANOFF, 1991). Segundo Rheingantz et al., (2007) este método permite aos indivíduos expressarem por meio de desenhos ou sentenças escritas suas necessidades, sentimentos e desejos relativos ao edifício ou ambiente analisado.

Após as visitas e aplicação dos questionários foram formuladas tabelas, plantas baixas e elevações para organizar os dados obtidos sobre o ambiente, perfil dos funcionários, tarefas e atividades realizadas, além das análises antropométricas com o objetivo de produzir recomendações que contribuam para a melhora da qualidade ambiental do restaurante e bem-estar de seus usuários.

\section{ANÁLISE DOS RESULTADOS}

Os resultados a seguir estão organizados em 5 seções: 4.1) Caracterização dos usuários; 4.2) O Ambiente Construído; 4.3) Tarefa x Atividade; 4.4) Análise antropométrica e 4.5) Conforto ambiental.

\subsection{Caracterização dos usuários}

Os usuários do restaurante podem ser classificados como clientes e funcionários. O foco deste trabalho será nos funcionários. A caracterização da amostra é composta por quatro atendentes, três cozinheiras, um apoio e um caixa que é o proprietário do restaurante. Todos os funcionários do atendimento e da cozinha são do sexo feminino, com faixa etária entre 18 e 42 anos, sendo a menor estatura, $1,54 \mathrm{~m}$ e, a maior, $1,70 \mathrm{~m}$. Foi identificado que todas tinham experiências anteriores e praticavam exercícios físicos. Já o caixa e o apoio são do sexo masculino, com idade de 43 e 35 anos e, estatura de $1,81 \mathrm{~m}$ e $1,91 \mathrm{~m}$, respectivamente. Todos são destros com exceção do funcionário que faz o apoio. O horário de trabalho dos funcionários é das 8:00 às 14:00 horas, sendo que o restaurante não abre nos finais de semana. À noite, o estabelecimento funciona como PUB, mas este turno não faz parte da avaliação deste artigo, pois são outros funcionários que trabalham neste horário.

\subsection{O Ambiente Construído}

O objeto deste estudo localiza-se em contexto urbano, em um terreno de esquina, próximo a 


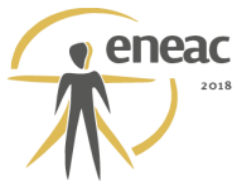

Universidade Federal de Santa Catarina, em uma rodovia importante na cidade de Florianópolis. Possui uma área 215,65 $\mathrm{m}^{2}$ dividida em dois setores: o salão com $117,65 \mathrm{~m}^{2} \mathrm{e}$ a cozinha com $38 \mathrm{~m}^{2}$. Em média o restaurante serve 250 refeições no horário do almo ço no período letivo da universidade e 170 refeições nas férias (Figura 1).

Figura 1 - Planta baixa do restaurante.

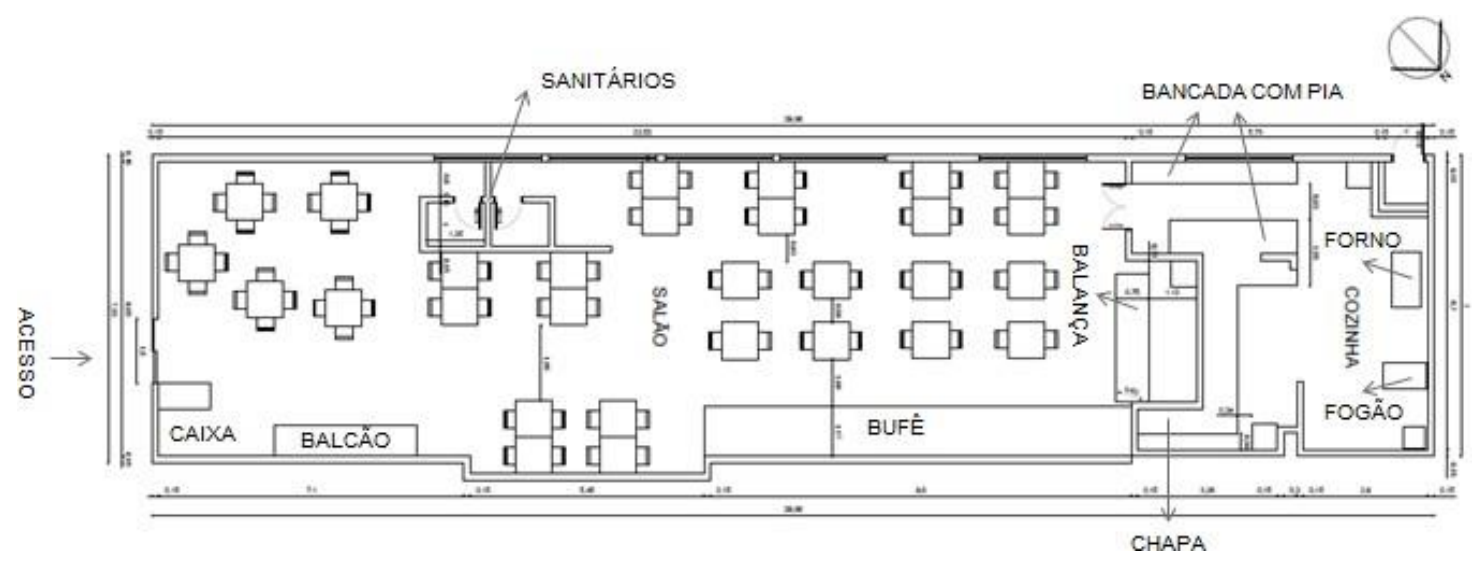

A edificação é feita de alvenaria com telhado cerâmico inclinado (uma água) para a orientação sudoeste. Sua área construída ocupa $100 \%$ do terreno. A parede norte fica na divisa, não tendo aberturas. As aberturas apresentam boas dimensões, presente na fachada frontal e lateral do restaurante com orientação sudoeste e sudeste e ventilação natural quando abertas. No geral, permanecem fechadas para a refrigeração artificial no ambiente. A planta baixa do salão tem forma longitudinal, com piso cerâmico na cor branca e forro de PVC branco colocado sobre a estrutura do telhado (longarinas) que tem cor escura. As paredes do ambiente são predominantemente brancas, mas a parede do bufê é pintada na "cor salmão". O mobiliário do salão é composto por balcão do caixa, próximo à entrada, o bufê, o balcão da balança de pesagem, um balcão com chopeira, dois freezers e 28 mesas, sendo 13 com quatro lugares e 15 com dois lugares (67 lugares) (Figura 2).

Figura 2 - Imagens da implantação, da fachada principal e interna do salão.
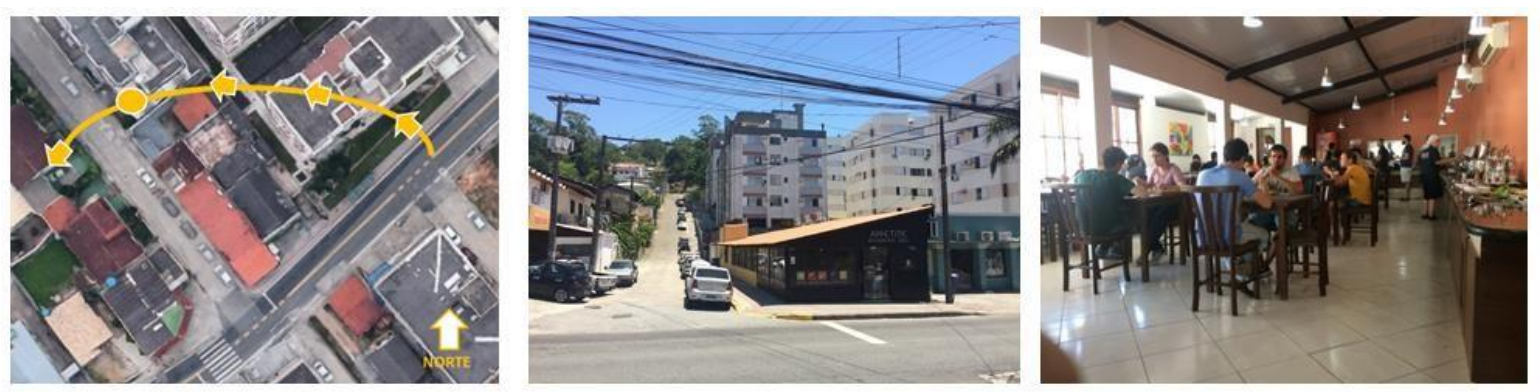

A cozinha fica localizada no fundo da edificação, tendo os mesmos revestimentos de piso e forro do salão, porém com revestimento cerâmico na cor branca em todas as paredes. A mesma é composta por quatro balcões e duas pias, três freezers, um forno, um fogão com coifa e uma chapa que faz conexão com o salão (Figura 3). 


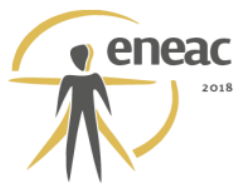

Figura 3 - Imagens do salão da porta da cozinha e da cozinha.
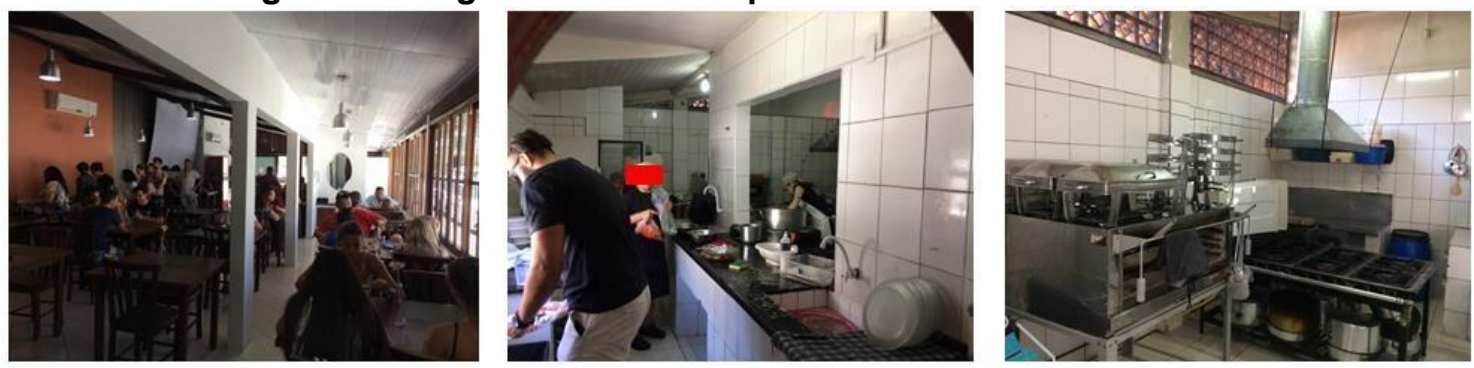

Não há espaço exclusivo para guardar as mercadorias, que ficam de forma improvisada embaixo do balcão do bufê no salão. O restaurante não possui ambientes que proporcionem um suporte social aos funcionários, como falta de um banheiro exclusivo e guarda pertences em local adequado. Por fim, é importante salientar que este estudo esta centrado no salão do restaurante, pois o acesso à cozinha foi restrito nas horas de maior movimentação.

\subsection{Tarefa $\mathrm{x}$ Atividade}

As entrevistas e as observações feitas resultaram no mapeamento das atividades realizadas pelos funcionários. Assim buscou-se na Classificação Brasileira de Ocupações (CBO), as tarefas a serem desenvolvidas pelos atendentes.

Tendo em vista as quatro atendentes, as respostas ao questionário apontam que as atividades desenvolvidas são condizentes com as tarefas previstas na CBO 5134 (Tabelas 01). Cerca de $50 \%$ das atividades é citada por mais de uma atendente, o que condiz com a observação feita pelos pesquisadores no local.

Tabela 1 - Tarefa x Atividades dos atendentes (pesquisadores e adaptação CBO 5134).

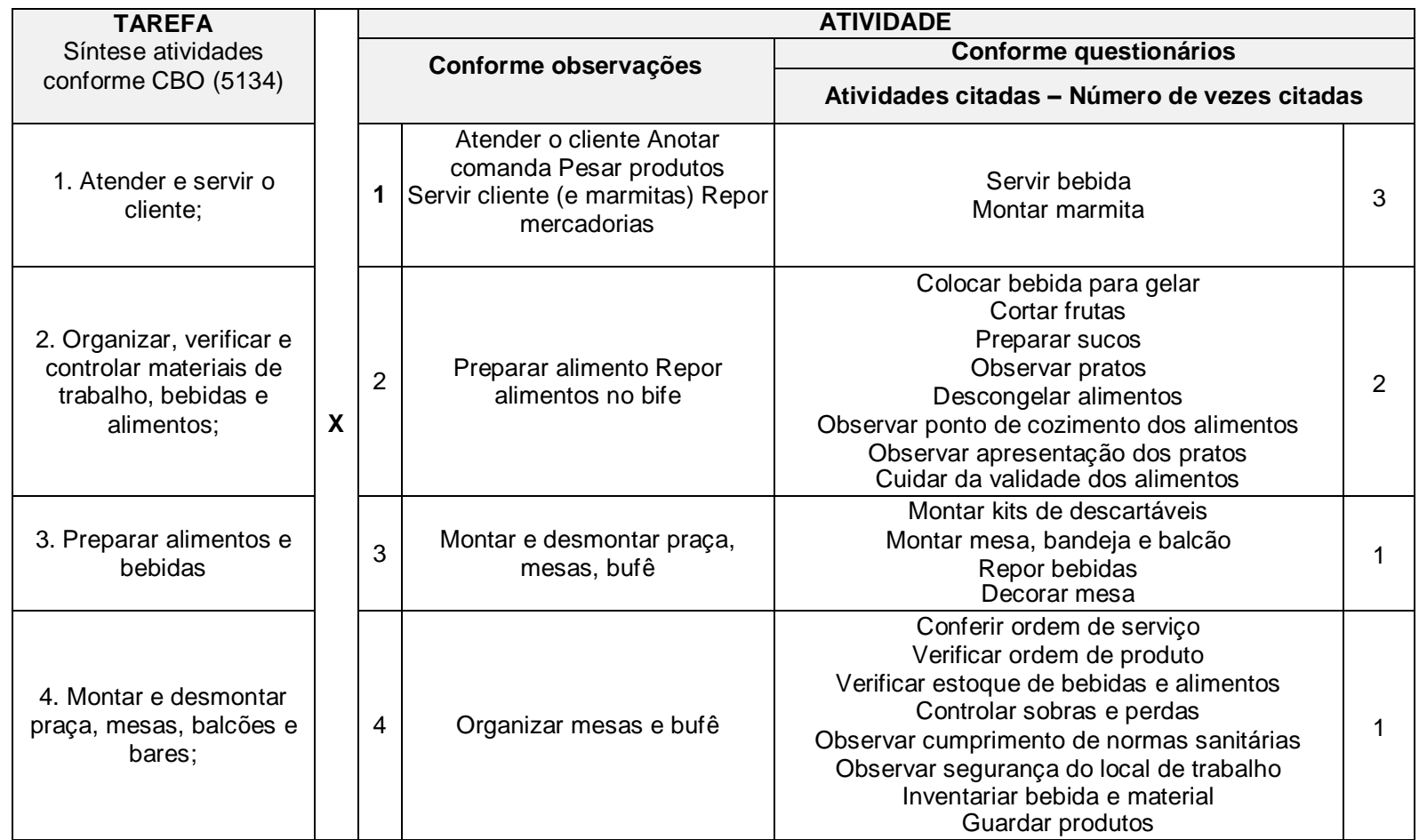




\begin{tabular}{|c|c|c|c|c|c|}
\hline \multirow{3}{*}{$\begin{array}{c}\text { TAREFA } \\
\text { Síntese atividades } \\
\text { conforme CBO (5134) }\end{array}$} & \multirow{4}{*}{$\mathbf{x}$} & \multicolumn{4}{|c|}{ ATIVIDADE } \\
\hline & & \multirow{2}{*}{\multicolumn{2}{|c|}{ Conforme observações }} & \multicolumn{2}{|l|}{ Conforme questionários } \\
\hline & & & & \multicolumn{2}{|c|}{ Atividades citadas - Número de vezes citadas } \\
\hline $\begin{array}{l}\text { 5. Higienizar utensílios e } \\
\text { equipamentos (incluindo } \\
\text { limpeza do mobiliário, piso } \\
\text { e separar lixo) }\end{array}$ & & 5 & Limpar mesas e piso & $\begin{array}{c}\text { Limpar equipamentos, mesa e bandejas } \\
\text { Separar lixo } \\
\text { Limpar piso } \\
\text { Lavar louça e utensílios }\end{array}$ & 2 \\
\hline 6. Extrair café & & 6 & Preparar café & Preparar café & 1 \\
\hline
\end{tabular}

\subsection{Análise antropométrica}

Para a análise antropométrica foram feitas medições das circulações e mobiliário do estabelecimento. Com estas informações foram elaborados croquis com os percentis de menor e maior estatura dos funcionários em alguns pontos críticos identificados. Também foi feito o mapa comportamental em três diferentes dias (14, 16 e 24 de Novembro de 2017) no horário do meio-dia.

Os atendentes percorrem "longas distâncias" para arrumar e repor o bufê e recolher os pratos devido à forma da planta baixa do salão ser linear. Também foi observado que a área 2 foi a de maior concentração de clientes, enquanto a área 1 foi a de menor permanecia de clientes. Isto se deve a distância entre a área 1 e a balança do bufê e, também, pelo conforto ambiental, já que esta área está mais exposta a radiação solar e ruídos vindos do exterior ( Figura 4).

Figura 4 - Mapa comportamental e conflitos nas circulações.

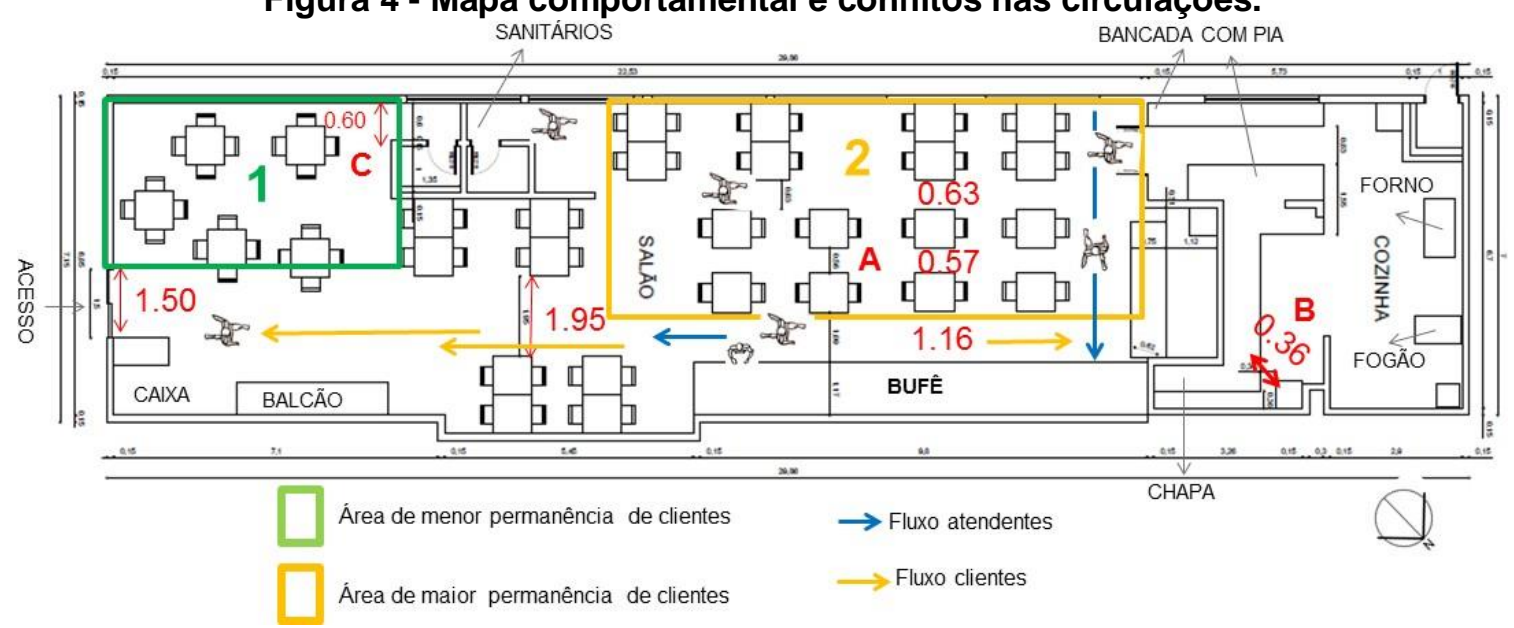

Uma circulação adequada proporciona aos usuários, clientes e funcionários, circularem sem esbarrar uns nos outros, permitindo a coexistência confortável das diferentes atividades, quais sejam: examinar os produtos do autosserviço, apreciar sua refeição, atender e servir o cliente, bem como organizar e repor produtos.

No entanto, o salão de atendimento apresenta conflito quanto às circulações, como apontado com letra (A) na Figura 04, cujas dimensões equivalem de 0,63 m, 0,57 m entre as mesas e $1.16 \mathrm{~m}$ entre as mesas e balcão do bufê, enquanto, segundo Panero e Zelnik (2017), o espaço mínimo previsto seria de $1.52 \mathrm{~m}$ a $1.67 \mathrm{~m}$. O acesso à chapa de carnes na cozinha (B) é de apenas $0.36 \mathrm{~m}$ e, o acesso aos banheiros (C), é de apenas $0.60 \mathrm{~m}$, abaixo da zona de circulação mínima recomendada de 0.76 m a 0.91m (PANERO; ZELNIK, 2017).

Foi observado que o acesso ao restaurante se dá apenas pela porta da frente, inclusive para 


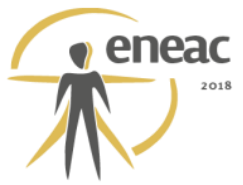

as mercadorias, que muitas vezes chegam no horário de maior fluxo do restaurante, causando ainda mais aglomeração entre pessoas. Os fluxos dos atendentes e clientes sobrepõem-se, especialmente, na circulação próxima ao bufê. A aglomeração de pessoas ocorre próxima ao café que fica localizado no inicio do balcão do bufê. Também nos horários de maior movimento pode ocorrer sobreposição das filas do bufê e do caixa, dificultando a movimentação dos atendentes (Figura 5).

\section{Figura 5 - Imagens dos fluxos no salão do restaurante.}
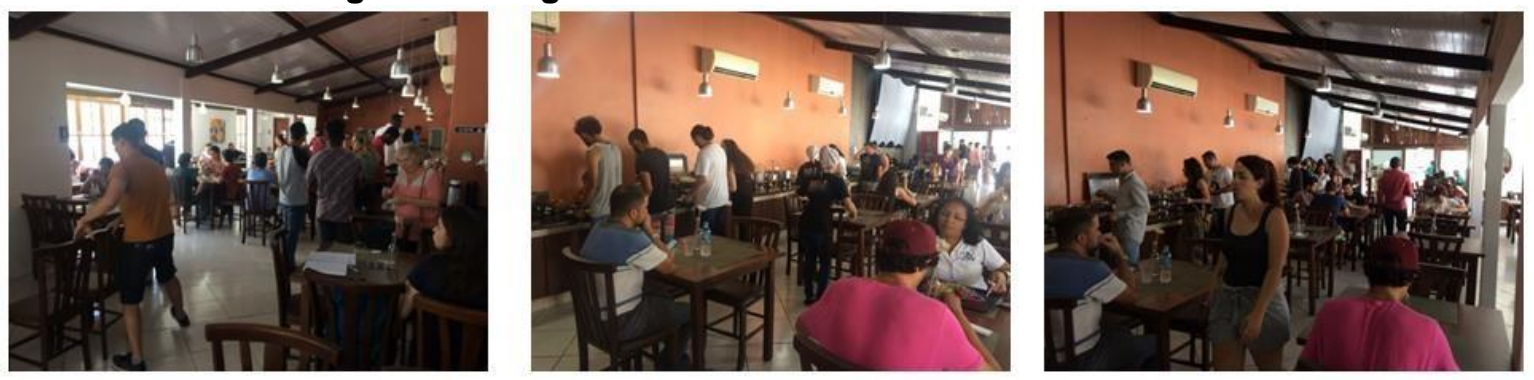

Os croquis da Figura 6 expressam as dificuldades da utilização da chapa (a) devido à largura do corredor de $0.38 \mathrm{~cm}$ e da utilização do balcão do Bufê (b) pelos funcionários que precisam de aproximadamente $0.72 \mathrm{~m}$ para movimentação adequada, porém como já citado, a largura neste local é de apenas $1.16 \mathrm{~m}$. Segundo Panero e Zelnik (2017), o espaço mínimo previsto para a chapa e para circulação do bufê seriam de $0.72 \mathrm{~m}$ e $1.67 \mathrm{~m}$, respectivamente.

a) Bancada da Chapa

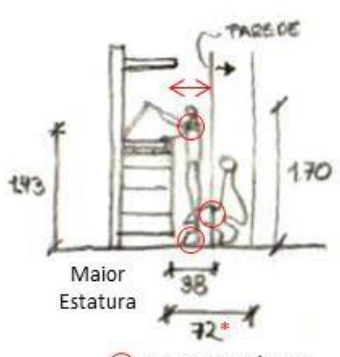

Pontos críticos

$\leftrightarrow$ Falta de espaço para movimentação

* Espaço mínimo indicado por Panero e Zelnik (2017)

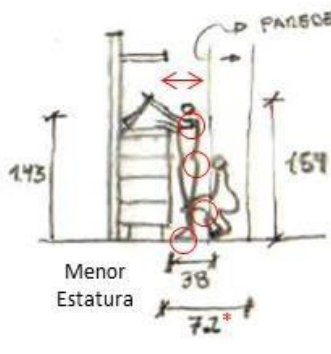

Figura 6 - Conflito quanto ao uso do mobiliário.

b) Bancada do bufê
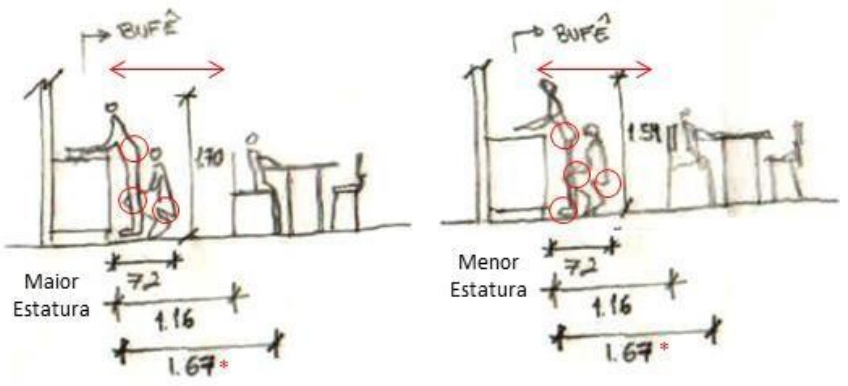

As condições de saúde física, no que diz respeito aos aspectos osteomusculares dos funcionários e, a relação dos mesmos com as atividades de trabalho, foi avaliada com o Questionário Nórdico. Os dados obtidos demonstram que não houve absenteísmo devido a distúrbios osteomusculares no último ano. Porém $42,85 \%$ dos funcionários sentiram dores na região dorsal e nos quadris e coxas, $28,57 \%$ no antebraço, região lombar, joelhos e tornozelos e pés e $14,28 \%$ nas outras regiões do corpo nos últimos 12 meses.

Quanto à avaliação referente aos últimos 7 dias, 14,28\% dos funcionários sentiram dor na região lombar, quadris e coxas e joelhos nos últimos 7 dias (Figura 7).

As dores sentidas em diferentes partes do corpo pelos funcionários podem estar associadas aos problemas espaciais detectados, já que os mesmos classificaram os fatores de projeto 


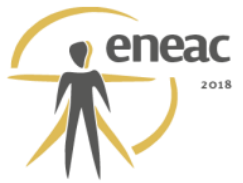

(aspectos funcionais), tais como, dimensionamento do mobiliário e distribuição do leiaute como ruins. Já nos poemas dos desejos foi mencionada a necessidade de espaços adequados para descanso. Nos formulários deste método não houve desenhos, apenas desejos expressos por escrita. Dentre os desejos apresentados pelos usuários, as palavras mais recorrentes foram: espaço aberto, mais ligações com a rua, mais espaço destinados aos funcionários e as mercadorias. Na observação dos traços físicos também confirmam aspectos relacionados à falta de espaço, conforme adaptações registradas na Figura 8.

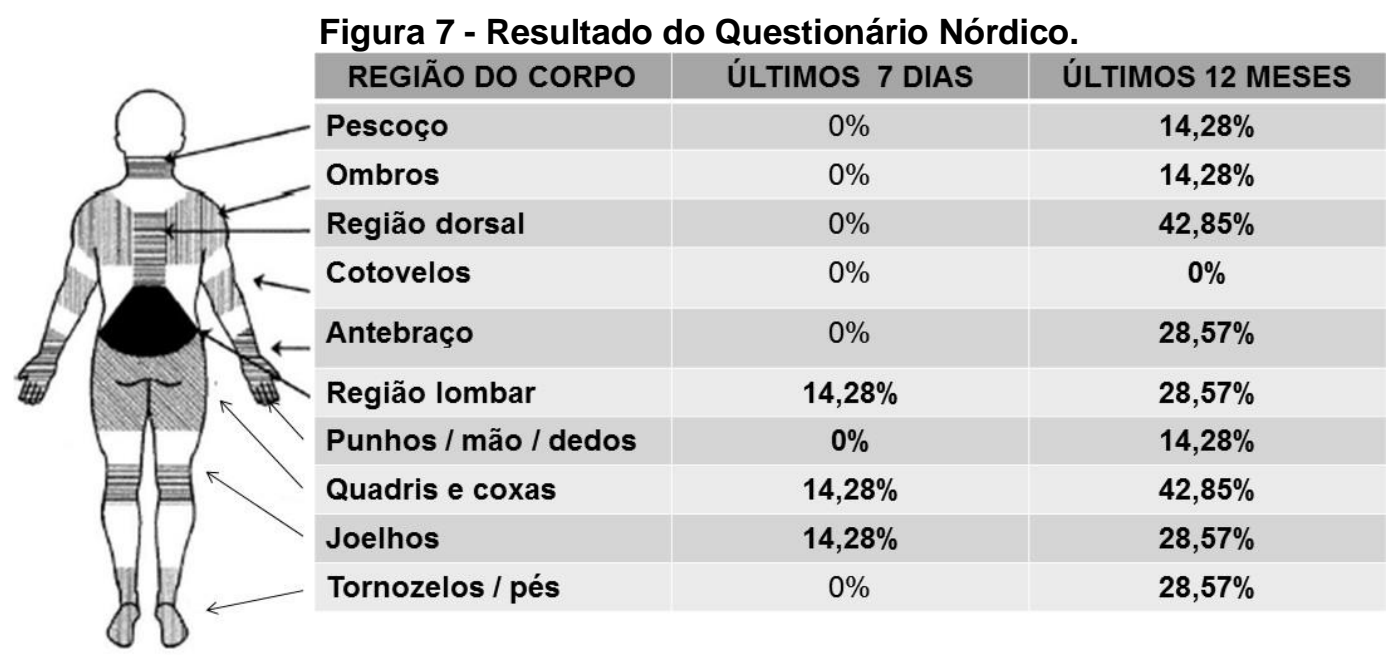

Figura 8 - Exemplos de adaptação de uso.
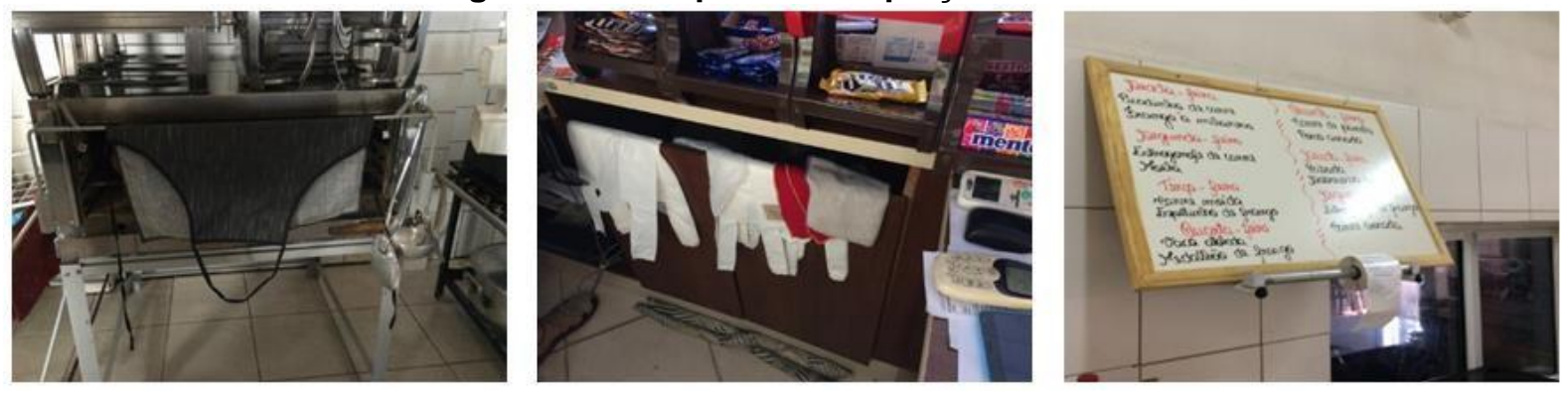

\subsection{Conforto Ambiental}

O conforto ambiental da edificação foi medido utilizando o aparelho MC 350. O aparelho que tem um sensor que capta informações sobre temperatura e umidade, ruído e iluminação foi colocado em diferentes pontos no interior (ponto 1, 2, 3 e 4 em vermelho) do restaurante e, também, no exterior (ponto 5,6 e 7 em vermelho) no dia 16 de Novembro de 2017 no horário de meio-dia (Figura 9).

Um ambiente de refeições requer iluminação natural adequada ao consumo, exposição e conservação dos alimentos. Os padrões do nível de iluminamento para restaurante, segundo a NBR 5413 (1992) ficam entre 100 e 200 lux. Foi observada uma variação de 107 lux (ponto 1) a 1.134 lux ( ponto 3) dentro do salão. Esta variação acontece, principalmente, por causa da concentração das aberturas nas fachadas sudoeste e sudeste. Também é importante salientar que as luminárias ficaram ligadas em todo o período das observações. No exterior do restaurante a iluminância atingiu 98.961 lux. Também foi observado que em alguns pontos há ofuscamento devido ao reflexo do piso (Figura 9 e Tabela 2).

A NBR 10.152 (1987) recomenda para o projeto de ambientes internos, classificar o conforto 
acústico em faixas de valores de nível sonoro em função da finalidade de seu uso. No caso de restaurantes, para atender esta norma deve-se ter como meta de projeto acústico que os níveis de ruído interno permaneçam entre $40 \mathrm{~dB}$ e $50 \mathrm{~dB}$, sendo o valor inferior representativo da condição de conforto, e o valor superior como limite do nível sonoro "aceitável para a finalidade". Os valores solicitados pela Norma referem-se ao ambiente projetado nas condições de uso comum, mobiliado, mas sem a presença de usuários. Não existe, entretanto, recomendação relativa a tempos de reverberação para esses espaços (MOJOLLA et al., 2013). As medições do ruído ficaram entre $67 \mathrm{~dB}$ e $70 \mathrm{~dB}$ no horário de maior circulação de pessoas no interior do restaurante. Foi observado que o restaurante não tem nenhum elemento absorvedor e isolante acústico, porém o ruído não foi um incômodo durante todas as observações realizadas.

Figura 9 - Mapa dos pontos de medições do conforto ambiental.

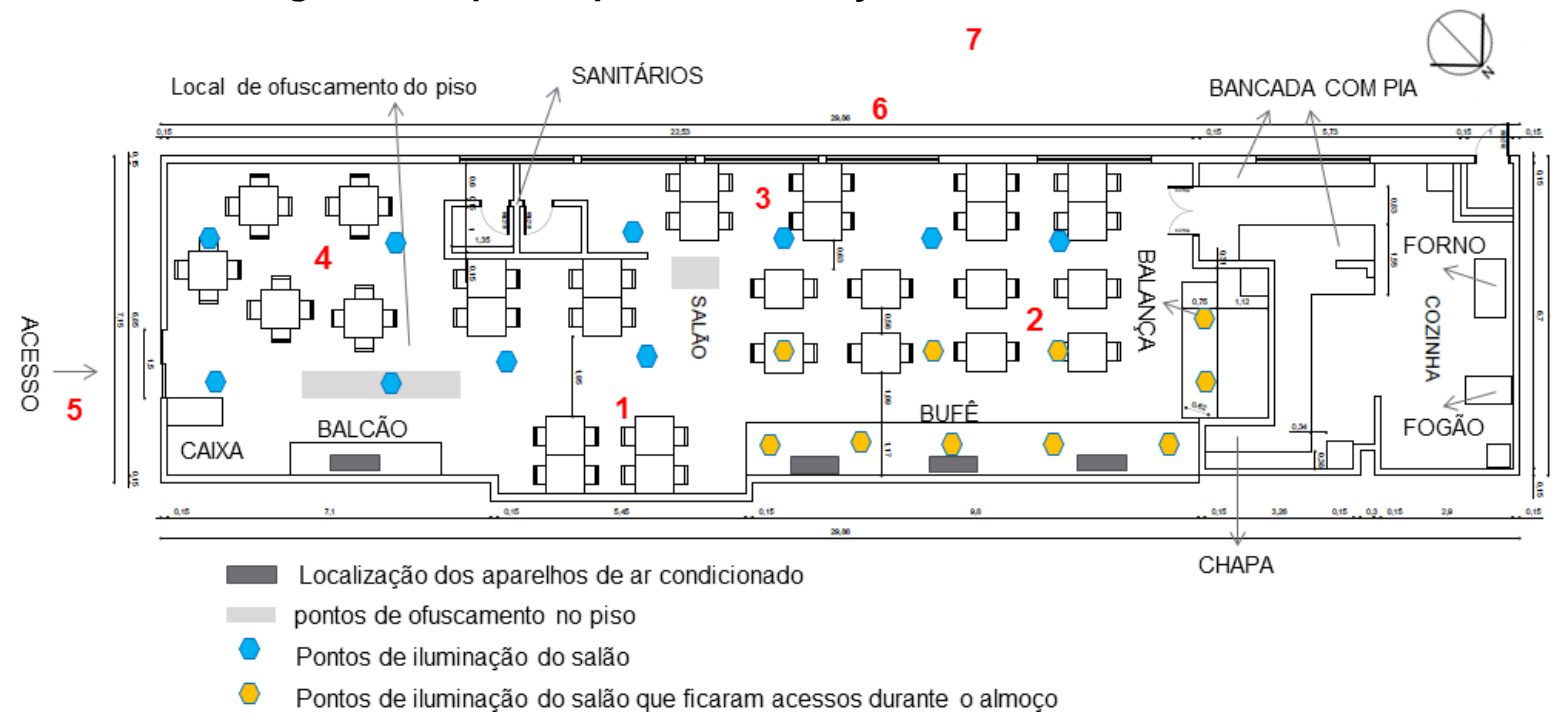

Tabela 2 - Conforto ambiental medidos em diferentes pontos

\begin{tabular}{|c|c|c|c|c|c|}
\hline $\mathbf{N}^{\circ}$ & Ambiente & Iluminação (lux) & Ruído (dB) & Temperatura $\left({ }^{\circ} \mathbf{C}\right)$ & Umidade (\%) \\
\hline 1 & Salão & 107 & 67 & 27,4 & 57 \\
\hline 2 & Salão & 111 & 70 & 28,3 & 62 \\
\hline 3 & Salão & 1.134 & 68 & 27,2 & 63 \\
\hline 4 & Salão & 933 & 69 & 29,7 & 66 \\
\hline 5 & Rua frontal & 98.961 & 71 & 37,5 & 50 \\
\hline 6 & Rua lateral & 98.961 & 68 & 40,8 & 44 \\
\hline 7 & Centro da rua & 98.961 & 70 & 44 & 33 \\
\hline
\end{tabular}

O conforto térmico varia de pessoa para pessoa e, também, está associado à atividade que se exerce no ambiente. Segundo Lamberts (2011), para pessoas com vestimenta normal de trabalho (Isolamento $=0,6 \mathrm{clo}$ ) a zona de conforto para que se mantenha o equilíbrio térmico situa-se entre $23^{\circ}$ e $27^{\circ} \mathrm{C}$. No dia 16 de Novembro de 2017 a temperatura máxima registrada na cidade de Florianópolis foi de $34^{\circ} \mathrm{C}$ e a mínima de $19^{\circ}$ graus. No interior do restaurante também havia um termômetro que marcava $33^{\circ} \mathrm{C}$ no horário do meio-dia. É importante mencionar que em todas as visitas, os cinco aparelhos de ar condicionado se mantiveram ligados com todas as janelas fechadas.

A variação de temperatura no ambiente interno foi entre $27,4^{\circ} \mathrm{C}$ (ponto 1 da Figura 9 ) à $29,7^{\circ} \mathrm{C}$ ( ponto 4 da Figura 9), esta variação se dá devido o ponto 4 estar mais próximo das janelas e, assim recebendo mais radiação solar devido a reflexão da radiação do entorno. Já no exterior a temperatura variou entre $37,5^{\circ} \mathrm{C}$ (ponto 5 da Figura 9) e $44^{\circ} \mathrm{C}$ ( Ponto 7 da 
Figura 9) no centro da rua.

Já a avaliação dos fatores ambientais feitas pelos funcionários apontam iluminação e som/barulho como ótimos, aroma/cheiro como bom e temperatura como regular. Esta avaliação regular no conforto térmico do restaurante pode ter ocorrido devido à falta de aparelhos de ar condicionado na cozinha. Neste ambiente não foi feito medições, pois não foi possível acesso no horário do almoço.

É Importante mencionar que para uma maior precisão destes resultados se faz necessário mais medições em diferentes dias e simulações computacionais para comparar os resultados. Por fim, estas medições serviram para ter um parâmetro para comparação com as respostas dos funcionários, que classificaram o ambiente nos quesitos iluminação, som/ barulho e aroma/cheiro como satisfatório e temperatura como regular. Isto mostra que a grande variação da iluminação no ambiente não chega a incomodar os funcionários, e que o conforto acústico, apesar de estar acima dos níveis de ruído recomendado pela NBR 10.152 (1987), é satisfatório. Já as medições do conforto térmico, que em todas as medições no salão ficaram um pouco acima do equilíbrio térmico $\left(23^{\circ}\right.$ e $27^{\circ} \mathrm{C}$.), confirmam a insatisfação dos funcionários.

\section{DIAGNÓSTICO E RECOMENDAÇÕES}

A Avaliação Pós-Ocupação possibilita o conhecimento das relações entre ambiente construído e comportamento dos usuários e, por consequência, permite detectar os padrões existentes e propor diretrizes para adaptações, reformas e novos projetos. Na sequência, são apresentados, na Tabela 03, os principais problemas diagnosticados e recomendações.

Tabela 3 - Principais problemas identificados e recomendações

\begin{tabular}{|c|c|}
\hline PROBLEMAS DIAGNOSTICADOS & RECOMENDAÇOES \\
\hline Odores provenientes da cozinha no salão & Recomenda-se trocar a coifa \\
\hline Conflito das filas do bufê e do cafezinho & $\begin{array}{c}\text { Trocar o "cafezinho" para a entrada, próximo ao caixa ou } \\
\text { para a parede do banheiro }\end{array}$ \\
\hline Sensação de calor em alguns pontos do salão & $\begin{array}{l}\text { Indica-se uso de proteção solar móvel na face interna do } \\
\text { salão }\end{array}$ \\
\hline Entorno: sem contato visual com a vegetação & Plantar árvores nas calçadas \\
\hline Ofuscamento em alguns pontos do salão & Indica-se uso de proteção solar móvel na face interna \\
\hline Pouco espaço para circulação no balcão da balança & Prever aumento do espaço e troca de leiaute. \\
\hline $\begin{array}{l}\text { O balcão do bufê serve para guardar mercadoria, causa } \\
\text { desconforto ergonômico aos funcionários e atrapalha a } \\
\text { circulação. }\end{array}$ & Prever ampliação para colocar as mercadorias \\
\hline $\begin{array}{l}\text { Banco do caixa não é confortável, o atendente do caixa fica muito } \\
\text { na posição em "pé". }\end{array}$ & Recomenda-se a troca da mesa e cadeira do caixa. \\
\hline Descanso funcionários & Prever ampliação para colocar um espaço para descanso \\
\hline Muito calor na cozinha & Colocar ventiladores e aumentar a ventilação natural \\
\hline A chegada de mercadoria atrapalha o fluxo do restaurante & Porta na fachada lateral para entrada de mercadoria \\
\hline Falta de contato com o exterior & Criar um espaço externo na rua lateral \\
\hline
\end{tabular}

Todos os problemas diagnosticados e recomendações foram identificados pela aplicação dos diferentes métodos utilizados nesta pesquisa. Porém as recomendações levam em consideração algumas observações do proprietário, tais como: o edifício é alugado, o proprietário assumiu a administração recentemente (2.5 anos) e já investiu em melhorias no local com margem de lucro pequena. Estes fatores inviabilizam uma ampliação imediata para resolver um dos principais problemas do estabelecimento que é falta de espaço para a mercadoria e área descanso e vestiário para os funcionários.

Como recomendações que não exigem grandes investimentos sugere-se a colocação de proteção solar interna, como uma simples cortina, a compra de ventiladores para a cozinha, 


\section{(x) $^{\text {enack }}$}

a troca da coifa, abertura de uma porta para a rua lateral e a colocação de parklets criando um espaço externo provisório para clientes e funcionários.

Os parklets são áreas contíguas às calçadas, onde são construídas estruturas a fim de criar espaços de lazer e convívio onde anteriormente havia vagas de estacionamento de carros. A concretização deste espaço é possível, pois a Câmara Municipal de Florianópolis aprovou no dia 06 de dezembro de 2016, o Projeto de Lei $n^{-15}$ 15.855/2016, que regulamenta a instalação e uso do parklet, extensão temporária de passeio público.

Estes são construídos como espaços efêmeros, com elementos construtivos de fácil montagem e desmontagem, utilizando madeira (exemplo: reaproveitamento de paletes) como material predominante, devido à sua versatilidade. Também é possível a colocação de vasos com plantas, o que beneficiará o conforto ambiental e visual do restaurante. Na Figura 10 são apresentados croquis da proposta elaborada como parte das recomendações feitas neste estudo.

Figura 10 - Croquis da proposta de um Parklet na rua lateral do restaurante.

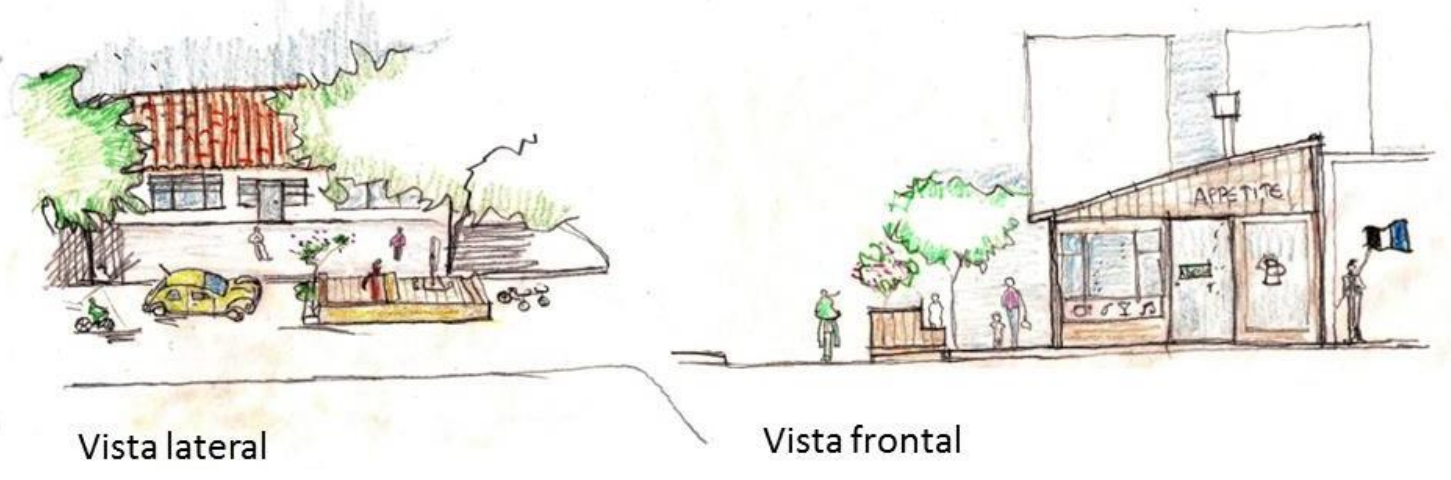

\section{CONCLUSÃO}

Quanto à atmosfera de restaurantes, é expressivo o número de pesquisas científicas, em especial das áreas da administração e marketing, focadas apenas em seu usuário final, 0 cliente. A ênfase da análise do ambiente em função de seus funcionários constitui um dos diferenciais dessa pesquisa, pois reconhece a importância de se atentar para seus usuários de maior permanência no espaço e dos vínculos que constitui com o mesmo.

As visitas exploratórias, entrevista e questionários, medições do conforto ambiental, pesquisa bibliográfica e documental permitiram caracterizar o ambiente, seus usuários e a estrutura organizacional da empresa. A investigação da relação biunívoca, entre indivíduos e o espaço, foi aprofundada por meio da observação direta. Já a análise antropométrica salientou problemas dimensionais quanto à usabilidade do espaço, em que se destacaram conflitos quanto ao subdimensionamento de circulações e de zona de utilização.

Os questionários apontaram a satisfação dos usuários quanto à ambiência do restaurante, porém com ressalvas para a temperatura, distribuição do leiaute e dimensionamento do mobiliário. Também se constatou a carência de suporte social, como área para descanso, vestiários e guarda-pertences.

A combinação de diferentes métodos das áreas da arquitetura, psicologia ambiental e ergonomia, aplicados de forma simultânea e complementar, possibilitou confirmar a maior parte das situações conflitantes levantadas e, também, conhecer outros aspectos só revelados por um método. O entrelaçamento dos resultados possibilitou conhecer os usuários da amostra, suas tarefas e atividades de trabalho, assim como a forma com que o 
ambiente dá suporte às suas necessidades. A partir do diagnóstico dos principais problemas foram feitas recomendações que visam proporcionar conforto, bem-estar e qualidade de vida aos usuários.

\section{REFERÊNCIAS BIBLIOGRÁFICAS}

ASSOCIAÇÃO BRASILEIRA DE NORMAS TÉCNICAS. NBR 5413 (NB 57) - lluminância de interiores. Rio de Janeiro, 1992.

NBR 10152 - Níveis de ruído para conforto acústico. Rio de Janeiro, 1987.

BRASIL, Ministério do Trabalho e Emprego. Classificação Brasileira de Ocupações. Disponível em: <http://www.mtecbo.gov.br/cbosite/pages/home. jsf>, acesso em 09 nov. 2013. IIDA, I. Ergonomia Projeto e Produção. São Paulo: Edgard Blücher, 2005.

KOPEC, Dak. Environmental Psychology for design. New York: Fairchild Publications, 2010. Capítulo 14.

KUORINKA, I; JONSSON, B; KILBON, A.; BIERING-SORENSEN, F.; ANDERSSON, G;

VINTERBERG, H.; JORGENSEN, K. Standardized Nordic Questionnaires for the Analysis of Musculoskeletal Symptoms. Applied Ergonomics, v. 18, n. 3, p. 233-37, 1987.

LAMBERTS, R. Conforto e strees térmico. Laboratório de Eficiência Energética em Edificações. Universidade Federal de Santa Catarina. Florianópolis, 2011.

ORNSTEIN, S. W. Arquitetura, Urbanismo e Psicologia Ambiental: uma reflexão sobre dilemas e possibilidades da atuação integrada. São Paulo: Revista Psicologia USP. 2005.

OJOLLA, R. et al. Conforto acústico em um restaurante universitário. XII Encontro Nacional e VIII Encontro Latino-Americano de Conforto no Ambiente Construído, 2013, Brasília- DP.

PANERO, J.; ZELNIK, M. Dimensionamento Humano para Espaços Interiores. Tradução: Anita R. Marco. Barcelona: Editorial Gustavo Gili, $1^{\text {a }}$ edição 2002, $12^{\mathrm{a}}$ impressão, 2017.

RHEINGANTZ; P. A. et al. Observando a qualidade do lugar: procedimentos para avaliação pósocupação. Rio de Janeiros: Universidade Federal do Rio de Janeiro, Faculdade de Arquitetura e Urbanismo, Pós-Graduação em Arquitetura, 2009.

Notas de aula da disciplina: Avaliação de Desempenho do Ambiente Construído. 2007. (apostila). Programa de Pós-graduação em Arquitetura, Faculdade de Arquitetura e Urbanismo, Universidade Federal do Rio de Janeiro, Rio de Janeiro, 2007.

SANOFF, Henry. Visual Research Methods in Design. Ed. John Wiley \& Sons Inc.,USA, 1991.

VOORDT, T. J. M.; WEGEN, H. B. R. Arquitetura sob o olhar do usuário: programas de necessidades, projeto e avaliação de edificações. São Paulo: Oficina de Textos, 2013.

ZEISEL, John. Inquiry by Design: Environmental/ Behavior/ Neuroscience in Architecture, Interiors, Landscape and Planning. New York, 2006. 